\title{
Tingkat Pengetahuan tentang Persiapan Kehamilan pada Remaja Putri di SMA Negeri 1 Sedayu Bantul Yogyakarta
}

\author{
Siti Nurunniyah ${ }^{1}$, Mulyanti $^{2}$, Rita Nur Octafiyani ${ }^{3}$ \\ 1, 2, 3Sekolah Tinggi Ilmu Kesehatan Alma Ata Yogyakarta \\ Jalan Ringroad Barat Daya No 1 Tamantirto, Kasihan, Bantul Yogyakarta
}

\begin{abstract}
Abstrak
Persiapan kehamilan harus dilakukan semenjak seorang perempuan masih remaja. Resiko terjadinya anemia, KEK, dan tidak merawat kehamilan sering terjadi akibat kurangnya pengetahuan. Penelitian ini merupakan penelitian deskriptif-kuantitatif dengan desain penelitian cross sectional. Sebanyak 118 siswi kelas XI di SMA Negeri 1 Sedayu Bantul Yogyakarta telah menjadi responden yang ditentukan dengan stratified random sampling. Kuisioner persiapan kehamilan digunakan sebagai instrumen pengumpulan data. Analisa univariat menunjukkan bahwa tingkat pengetahuan remaja terhadap persiapan kehamilan dikategorikan cukup (56\%/66 reponden). Indikator tingkat pengetahuan yang meliputi pengertian persiapan kehamilan dalam kategori baik (100\%); usia reproduksi sehat dalam kategori cukup (66\%/78 responden); imunisasi tetanus toxoid dalam kategori kurang (72\%/85 orang); asam folat dalam kategori baik (57\%/67 orang); anemia dikategorikan baik sebanyak 85 orang (72\%); dan status gizi pada kategori cukup (49\%/58 orang). Darimpulan rata-rata tingkat pengetahuan persiapan kehamilan di kategorikan cukup baik, sedangkan tingkat pengetahuan tentang persiapan kehamilan terutama tentang imunisasi Tetanus Toxoid dalam kategori kurang baik.
\end{abstract}

Kata Kunci: Tingkat pengetahuan, Persiapan kehamilan, Remaja putri.

\section{Degree of Knowledge Teen Women Students in Sedayu I Public High School Bantul Yogyakarta on Pregnance Preparation}

\begin{abstract}
Pregnancy preparation has to be undertaken since women in teenage. The risk of anemia, KEK, and neglegance of pregnancy causes by poor knowledge. This is a descriptive quantitative research using crosssectional design. It was 118 of Sedayu I public high schools student participating in the research determined by stratified random sampling technique. Questioner of pregnancy preparation used as tool to collect data. Univariate analysis presents that degree of knowledge of preganancy preparation on teen students was average ((56\%/66 repondents). Indicators of degree of knowledge include definition in good category (100\%); understanding of ideal health reproduction in average (66\%/78 respondents); tetanus toxoid immunization in lower category (72\%/85 people); understanding of folic acid in average category (57\%/67 people); anemia in great category by 85 respondents (72\%); and diet status in average category (49\%/58 people). Conclusion, the level of knowledge of teen women students on the pregnancy preparation is mostly in good level, while, understanding of tetanus toxoid immunication is low.
\end{abstract}

Keywords: Pregnancy, Preparation Teenage Students

Info Artikel:

Artikel dikirim pada 13 November 2013

Artikel diterima pada 13 November 2013 


\section{Pendahuluan}

Sekitar $2-27 \%$ dari seluruh kematian perinatal disebabkan karena kelahiran prematur dengan berat lahir rendah (BBLR). Sementara itu prevalensi prematur di Indonesia diperkirakan $7-14 \%$ yaitu sekitar 459.200-900.000 bayi pertahun ${ }^{1}$. Tahun 2005 angka kejadian persalinan prematur di Rumah Sakit Indonesia sebanyak 3142 kasus dan pada tahun 2006 yaitu sebanyak 3063 kasus $^{2}$. Rumah Sakit Panti Rapih Yogyakarta angka kejadian kelahiran bayi prematur adalah sebesar $33,3 \%{ }^{3}$.

RSU PKU Muhammadiyah Bantul kejadian kelahiran bayi prematur sebesar $6,12 \%$. Perbaikan dalam angka kematian perinatal dapatdicapai dengan pemberian pengawasan antenatal untuk semua wanita hamildengan menemukan dan memperbaiki faktor-faktor yang mempengaruhi keselamatan janin dan neonatus ${ }^{4}$.

Di Provinsi DIY, akses ibu hamil terhadap tenaga kesehatan tanpa memandang umur kandungan saat kontak pertama kali (K1) cukup tinggi yaitu 92,7 \%, namun cakupan akses ibu hamil yang lengkap (K4) sebanyak 4 kali pada tiap trimester selama kehamilan dengan pola 1-1-2 oleh tenaga kesehatan masih belum optimal yaitu 61,4\%. Khusus untuk daerah Bantul, cakupan pemeriksaan ibu hamil K4 mencapai $85,48 \%$ dari target sebesar $95 \%$.
Meskipun demikian, diperlukan perhatian khusus karena penurunan angka kematian bayi masih jauh dari target. Salah satu aspek yang perlu dipertimbangkan adalah kualitas layanan ANC untuk memastikan diagnosis dini dan perawatan yang tepat, di samping pendekatan kesehatan ibu hamil yang terpadu dan menyeluruh ${ }^{6}$. Berdasarkan hasil studi pendahuluan yang dilakukan di RS Panembahan Senopati Bantul dari 1 Januari 2011 hingga 29 Februari 2012, proporsi kelahiran bayi prematur dari 2543 orang ibu bersalin adalah 8,13\%. Tujuan penelitian ini untuk mengetahui hubungan antara frekuensi kunjungan Antenatal Care (ANC) dengan kejadian prematur di Kabupaten Bantul Yogyakarta.

\section{Bahan dan Metode}

Penelitian ini menggunakan metode observasional dengan rancangan penelitian studi case control. Sampel dalam penelitian ini adalah ibu dengan bayi prematur di RSUD Panembahan Senopati, Bantul, Yogyakarta, sedangkan teknik pengambilan sampmenggunakan tehnik acak sederhana (Simple Random Sampling) dengan jumlah 156 orang, yaitu 78 orang responden untuk kasus dan 78 orang responden untuk control di Kabupaten Bantul Provinsi Daerah istimewa Yogyakarta.

Tabel 1. Karakteristik Responden (Ibu Hamil) di Kabupaten Bantul

\begin{tabular}{|c|c|c|c|c|c|c|c|c|}
\hline \multirow{3}{*}{ No } & \multirow{3}{*}{\multicolumn{2}{|c|}{ Karakteristik }} & \multicolumn{4}{|c|}{ Responden } & \multirow{3}{*}{$x^{2}$} & \multirow{3}{*}{$P$-value } \\
\hline & & & \multicolumn{2}{|c|}{ Kasus } & \multicolumn{2}{|c|}{ Kontrol } & & \\
\hline & & & $\mathrm{n}$ & $\%$ & $\mathrm{n}$ & $\%$ & & \\
\hline \multirow[t]{4}{*}{1.} & Umur & & & & & & & \\
\hline & a. & $<20$ tahun $>35$ tahun & 21 & 23 & 34 & 44 & 4,746 & 0,029 \\
\hline & & $20-35$ tahun & 57 & 73 & 44 & 56 & & \\
\hline & & & 78 & 100 & 78 & 100 & & \\
\hline \multirow[t]{5}{*}{2.} & Pendidil & $\tan$ & & & & & & \\
\hline & a. & Rendah (SD) & 15 & 19,2 & 8 & 10,3 & 3,543 & 0,170 \\
\hline & & Sedang (SMP-SMA) & 61 & 78,2 & 6,5 & 83,3 & & \\
\hline & & Tinggi (PT) & 2 & 2,6 & 5 & 6,4 & & \\
\hline & & & 78 & 100 & 78 & 100 & & \\
\hline \multirow[t]{4}{*}{3.} & Paritas & & & & & & & \\
\hline & a. & $\geq 4$ & 69 & 88 & 13 & 17 & 80,622 & 0,0001 \\
\hline & & $<4$ & 9 & 12 & 65 & 83 & & \\
\hline & & & 78 & 100 & 78 & 100 & & \\
\hline \multirow[t]{7}{*}{4.} & $\begin{array}{c}\text { Riwayat } \\
\text { a. }\end{array}$ & $\begin{array}{l}\text { Penyakit/penyulit keha } \\
\text { Sebelumnya }\end{array}$ & & & & & & \\
\hline & 1) & Ada & 35 & 45 & 49 & 73 & 5,056 & 0,25 \\
\hline & 2) & Tidak & 43 & 55 & 29 & 37 & & \\
\hline & & Sekarang & & & & & & \\
\hline & 1) & Ada & 27 & 35 & 54 & 69 & 18,720 & 0,001 \\
\hline & 2) & Tidak & 51 & 65 & 25 & 31 & & \\
\hline & Total & & 78 & 100 & 100 & 100 & & \\
\hline
\end{tabular}

Sumber: Data Primer 2012 


\section{Hasil Dan Pembahasan}

\section{Karakteristik Subyek Penelitian}

Variabel umur menunjukkan hubungan yang signifikan dengan kejadian prematur $(p=0,029)$. Menurut Departemen Kesehatan RI, umur <20 dan $>30$ tahun dianggap sebagai faktor risiko yang secara tidak langsung meningkatkan kejadian BBLR dan prematur. Responden dengan pendidikan tinggi berjumlah 7 orang atau $4 \%$, serta responden dengan pendidikan rendah dan sedang masingmasing berjumlah 23 orang atau 15\% dan 126 orang atau $81 \%$. Dari hasil analisis tabel diatas dapat dikatakan bahwa variabel pendidikan tidak memiliki hubungan yang signifikan dengan kejadian premature $(p=0.170)$.

Berdasarkan paritas atau jumlah anak yang dilahirkan, responden dengan paritas $\geq 4$ memiliki jumlah lebih besar daripada responden dengan paritas $<4$. Responden dengan paritas $\geq 4$ berjumlah 82 orang atau $53 \%$ dan responden dengan paritas $>4$ berjumlah 74 orang atau $47 \%$. Analisis tabel diatas dapat dikatakan bahwa paritas memiliki hubunganyang signifikan dengan kejadian prematur $(p=0,000)$. Pada riwayat kehamilan sebelumnya tidak terdapat hubungan yang signifikanantara riwayat kehamilan sebelumnya dengan kejadian prematur $(p=0,25)$. Sedangkan pada riwayat kehamilan sekarang didapatkan bahwa riwayat kehamilan sekarang/ penyulit yang menyertai kehamilan memiliki hubungan yang signifikan dengan kejadian prematur $(p=0,000)$. Paritas atau jumlah anak yang dilahirkan berpengaruh dimana paritas lebih dari 3 akanmeningkatkan risiko kelahiran prematur ${ }^{7}$.

Hasil penelitian dari Christine (2004) menunjukkan bahwa secara signifikan paritas merupakan risiko terhadap kelahiran prematur. ${ }^{8}$ Riwayat kehamilan sekarang dapat dikatakan sebagai penyakit atau penyulit yang menyertai kehamilan seperti pendarahan antepartum, preeklampsi dan Ketuban Pecah Dini (KPD), yang akan meningkatkan kejadian prematuritas adalah perdarahan antepartum ${ }^{7}$. Hal ini dikarenakan perdarahan yang hebat pada ibu sehingga janin harus dilahirkan walaupun usia kehamilan masih premature ${ }^{9}$.
Tabel 2. Distribusi Frekuensi Responden Berdasarkan Waktu Pertama Kunjungan ANC (K1)

\begin{tabular}{lcccc}
\hline \multirow{2}{*}{$\begin{array}{c}\text { Waktu Pertama } \\
\text { ANC }\end{array}$} & \multicolumn{4}{c}{ Kesponden } \\
\cline { 2 - 5 } & $N$ & $\%$ & $n$ & $\%$ \\
\hline 0-3 bulan & 71 & 91,0 & 69 & 88,5 \\
4-6 bulan & 6 & 7,7 & 9 & 11,5 \\
6-9 bulan & 1 & 1,3 & - & - \\
& 78 & 100 & 78 & 100 \\
\hline
\end{tabular}

Sumber : Data Primer 2012

Berdasarkan tabel 2. ketahui bahwa seluruh ibu yang melahirkan bayi prematur pernah melakukan kunjungan ANC selama hamil. Sebanyak 71 orang ibu (91\%) melakukan ANC untuk pertama kali (K1) pada usia kehamilan 0-3 bulan (trimester I). Hanya 1 orang ibu (1,3\%) yang melakukan kunjungan ANC pertama kali pada kehamilan usia 6-7 bulan (trimester III).

Tabel 2. juga menunjukkan bahwa sebanyak 69 orang $(88,5 \%)$ responden yang melahirkan bayi normal, melakukan kunjungan ANC pertama kali pada usia kehamilan 0-3 bulan. Hanya 9 orang $(11,5 \%)$ responden yang melakukan kunjungan ANC pada usia kehamilan 4-6 bulan. Persentase inilebih rendah dibandingkan dengan persentase K4 Kabupaten Bantul tahun 2010, dimana cakupan K4 pada tahun tersebut mencapai $85,48 \%{ }^{6}$.

Tabel 3. Distribusi Frekuensi Responden Berdasarkan Frekuensi ANC Kunjungan lengkap (K4)

\begin{tabular}{lcccc}
\hline \multirow{2}{*}{ ANC } & \multicolumn{4}{c}{ Responden } \\
\cline { 2 - 5 } & \multicolumn{3}{c}{ Kasus } & \multicolumn{3}{c}{ Kontrol } \\
\cline { 2 - 5 } & $N$ & $\%$ & $n$ & $\%$ \\
\hline Tidak K4 & 15 & 19,2 & 14 & 17,9 \\
K4 & 663 & 80,8 & 64 & 82,1 \\
\hline Total & 78 & 100 & 78 & 100 \\
\hline
\end{tabular}

Sumber : Data Primer 2012

Tabel 3 menunjukkan bahwa sebanyak 63 orang $(80,8 \%)$ ibuyang melahirkan bayi prematur, mempunyai riwayat ANC saat hamildan 15 orang $(19,2 \%)$ ibu yang melahirkan bayi premature tidak melakukan ANC ketika hamil. Tabel tersebut juga menunjukkan bahwa sebanyak 14 orang $(17,9 \%)$ ibu melahirkan bayi normal

Tabel 4 Tabulasi Silang dan Uji Chi Square Kunjungan ANC Terhadap Persalinan Prematur di Kabupaten Bantul 2012

\begin{tabular}{|c|c|c|c|c|c|c|c|c|}
\hline \multirow[t]{2}{*}{ Karakteristik } & \multicolumn{4}{|c|}{ Responden } & \multicolumn{2}{|c|}{ Jumlah } & \multirow[t]{2}{*}{$\mathrm{x}^{2}$} & \multirow[t]{2}{*}{$p$-value } \\
\hline & $f$ & $\%$ & $f$ & $\%$ & $f$ & $\%$ & & \\
\hline Tidak K4 & 15 & 51,7 & 14 & 48,3 & 29 & 100 & 0,43 & 0,837 \\
\hline K4 & 127 & 49,6 & 64 & 50,4 & 127 & 100 & & \\
\hline Total & 78 & 100 & 78 & 100 & 156 & 100 & & \\
\hline
\end{tabular}

Sumber : Data Primer 2012 
tidakmelakukan kunjungan lengkap ANC (K4) ketika hamil dan 64 orang $(82,1 \%)$ responden melakukan kunjungan ANC (K4) ketika hamil.

Berdasarkan tabel 1.4 diketahui bahwa jumlah responden baik kelompok kasus maupun kontrol yang tidak melakukan ANC (K4) yaitu sebanyak 29 orang. Sebanyak 15 orang $(51,7 \%)$ mengalami persalinanprematur dan 14 lainnya $(48,3 \%)$ mengalami persalinan normal. Sedangkan jumlah responden yang melakukan ANC (K4) yaitu sebanyak127 orang. Dari jumlah tersebut terdapat 63 orang $(49,6 \%)$ mengalami persalinan prematur dan 64 orang $(50,4 \%)$ mengalami persalinan normal. Hasil uji statistik dengan menggunakan chi square didapatkan nilai $p$ value sebesar $0,837(p>0,05)$.

Tebel 5 Koefisien Determinasi dari Variabel Umur, Paritas dan Riwayat Penyakit Sekarang

\begin{tabular}{lcc}
\hline & $\mathrm{R}$ & $\mathrm{R}$ Square \\
\hline Umur, Paritas, Riwayat Kehamilan & 0,779 & 0,607 \\
Sekarang & & \\
\hline
\end{tabular}

Sumber : Data Primer 2012

Hubungan variabel umur, paritas dan riwayat penyakit sekarangdengan kejadian prematur menunjukkan hubungan yang cukup kuat $(R=0,779)$. Nilai R Square atau koefisien determinasi yang diperoleh adalah $60,7 \%$ yang dapat ditafsirkan bahwa variabel bebas (umur, paritas dan riwayat penyakit) memiliki pengaruh kontribusi sebesar $60,7 \%$ terhadap variabel dependent (kejadian prematur)dan 39,3\% lainnya dipengaruhi oleh faktor-faktor lain di luar variabel bebas.

Tebel 6 Regresi Linier : Hubungan variabel dependent dengan umur, paritas, riwayat penyakit sebelum dan selama kehamilan.

\begin{tabular}{clccc}
\hline No & Model & Coefficients B & T & p-value \\
\hline 1 & (Constant) & 1,007 & 19,349 & 0,0001 \\
2 & Umur & 0,013 & 0,175 & 0,861 \\
3 & Paritas & 0,694 & 11,228 & 0,0001 \\
4 & Riw_hml_skrng & 0,307 & 4,837 & 0,0001 \\
\hline
\end{tabular}

Sumber : Data Primer

Hasil perhitungan menunjukkan bahwa paritas mempunyai nilai koefisien beta lebih besar dibandingkan dengan variabel-variabel lainnya yaitu sebesar 0,693. Hal ini menunjukkan bahwa paritas merupakanvariabel yang paling dominan berpengaruh terhadap kejadian prematur di Kabupaten Bantul tahun 2011-2012. Variabel umur diperoleh nilai probability $0,861>0,05$, sehingga secara statistik umur tidak memiliki hubungan yang signifikan dengan kejadian prematur. Variabel paritas dan riwayat kehamilan sekarang diperoleh nilai probability $0,000<0,05$, sehingga secara statistik paritas dan riwayat kehamian sekarang memilikihubungan yang signifikan dengan kejadian prematur.

Insiden prematur pada Januari 2011 sampai dengan Februari 2012 di RSUD Panembahan Senopati Bantul adalah 8,13\% dari jumlah kelahiran atau 82 orang dalam 1000 kelahiran. Salah satu penyebab kelahiran premature adalah kunjungan ANC. Krisnadi (2009) berpendapat bahwa dengan pemeriksaan kehamilan sesuai standar maka akan terdeteksi kondisi yang dapat menyebabkan bayi dengan risiko lahir prematur ${ }^{10}$ Standar pelayanan kebidanan menetapkan sedikitnya empat kali pelayanan antenatal selamakehamilan ibu, satu kali kunjungan pada trimester I, satu kali pada trimester II,dan dua kali kunjungan pada trimester III. Pada setiap kunjungan ANC bidan harus menanyakan apakah ibu hamil meminum tabelt besi sesuai dengan ketentuan dan apakah persediaannya cukup ${ }^{11}$.

Dalam penelitian ini diketahui bahwa frekuensi kunjungan ANC tidak berhubungan dengan kelahiran prematur di RSUD Panembahan Senopati Bantul, hal ini dapat disebabkan oleh kualitas pelayanan ANC yang kurang optimal. Dinkes Kabupaten Bantul (2012) menyatakan bahwa kunjungan antenatal yang terpenting adalah kualitasnya bukan kuantitasnya. Hasil penelitian dari Sistriani (2008), bahwa ibu yang memiliki kualitas pelayanan antenatal yang kurang baik mempunyai peluang melahirkan BBLR/prematur 5,85 kali dibandingkan ibu yang memiliki kualitas pelayanan antenatal baik ${ }^{12}$. Kualitas dari pelayanan ANC yang diberikan kepada ibu hamil yang kurang tepat dapat menyebabkan ibu dengan risiko prematur tidak mendapatkan pengobatan dan perawatan dengan segera. Persalinan prematur tidak hanya disebabkan oleh faktor kualitas pelayanan ANC yang kurang optimal tetapi juga disebabkan oleh beberapa faktor lain. Pada penelitian ini didapatkan bahwa faktor yang memberi pengaruh paling signifikan adalah paritas $(p=0,000)$ dan riwayat kehamilan sekarang $(p=0,000)$. Paritas adalah jumlah anak yang telah dilahirkan oleh seorang ibu baik lahir hidup maupun lahir mati. Sedangkan paritas adalah jumlah kehamilan yang dilahirkan atau jumlah anak yang dimiliki baik dari hasil perkawinansekarang atau sebelumnya ${ }^{13}$.

Ketuban Pecah Dini (KPD) juga ikut memberikan pengaruh terhadap tingginya angka prematuritas, sesuai hasil penelitian Andriyani 
2009 bahwa ada hubungan antara ketuban pecah dini dengan kejadian prematur ${ }^{4}$. Faktor lain yang ikut berpengaruh adalah umur, dimana umur ibu yang kurang dari 25 dan lebih dari 35 tahun akan memberikan risiko terhadapmeningkatnya kejadian prematur. Menurut hasil penelitian Chiristine (2004) nunjukkan bahwa faktor lain yang berhubungan dengan kejadian premature adalah riwayat plasenta previa ibu dan kehamilan kembar ${ }^{8}$. Varney (2007) menambahkan bahwa setiapwanita yang telah mengalami kelahiran prematur pada kehamilan terdahulu memiliki risiko 20 sampai 40 persen untuk terulang kembali (Varney, 2007). ${ }^{13}$ Menurut Mochtar (2002) persalinan prematur sulit diduga dan sulit dicaripenyebabnya, sehingga pengobatannya sukar diterapkan dengan pasti ${ }^{14}$.

\section{Simpulan dan Saran}

\section{Simpulan}

Kasus prematur di RSUD Panembahan Senopati Bantul selama periode 1Januari 2011 sampai 29 Februari 2012, ditemukan 207 kasus atau 8,13\% ibu yang melahirkan bayi prematur. Sebanyak 80,8\% ibu melahirkan prematur melakukan kunjungan ANC sebanyak 4 kali atau lebih dengan pola 1-1-2 tiap semesternya dan sebanyak $82,1 \%$ ibu melahirkan normal melakukan kunjungan ANC sebanyak 4 kali atau lebih dan dengan pola 1-1-2 tiap semesternya. Berdasarkan hasil analisis penelitian hubungan frekuensi kunjunganAntenatal Care (ANC) dengan kejadian prematur di Kabupaten Bantul didapatkan nilai $p$-value sebesar 0,837 ( $p>0,05)$. Disimpulkan bahwa secara statistik frekuensi kunjungan ANC tidak berhubungan dengan kejadian prematur di Kabupaten Bantul.

\section{Saran}

Diharapkan kepada ibu hamil untuk menghindari faktor risiko kelahiran prematur diantaranya adalah dengan menjarangkan kelahiran menjadi lebih dari 3 tahun, merencanakan kehamilan pada umur 2035 tahun, memiliki anak tidak lebih dari 4 orang dan sebisa mungkin memilih tempat pelayanan dengan petugas kesehatan yang dapat memberikan pelayanan ANC dengan kualitas yang baik.

\section{Daftar Pustaka}

1. Depkes RI. 2005. "Kesakitan dan Kematian bayi dalam intisari Depertemen Kesehatan Republik Indonesia" dalam http://www.depkes.go.id. 20 Januari2012.

2. Setyorini, A. 2009. "Preeklampsi/Eklampsia dan Risiko Kelahiran Preterm di Rumah Sakit Panti Rapih Yogyakarta" dalam Jurnal Kesehatan.7 (2): 74-89.

3. Andriyani, A.D. 2009. Hubungan Ketuban Pecah Dini dengan Kejadian Partus Prematurus di RSU PKU Muhammadiyah Bantul tahun 2007 - 2008. Karya Tulis IImiah Stikes Aisyiyah Yogyakarta.

4. Prawirohardjo, S. 2002. IImu Kebidanan. Jakarta: Yayasan Bina Pustaka.

5. Dinkes Kabupaten Bantul. 2010.Profil Kesehatan Kabupaten Bantul. Yogyakarta: Direktorat Jenderal Pelayanan Medik.

6. Suririnah. 2008. Buku Pintar Kehamilan dan Persalinan. Jakarta: Gramedia Pustaka Utama.

7. Chiristine, R.E. 2004. Analisis Faktor Resiko dan Hubungannya dengan Kelahiran Preterm (Prematur) di Rumah Sakit Ibu dan Anak Badrul Aini Medan tahun 2002-2003. Skripsi Universitas Sumatra Utara Medan.

8. Manuaba, I. B. 2007. Pengantar Kuliah Obstetri. Jakarta: EGC.

9. Krisnadi, S.R. 2009. "Faktor Resiko Persalinan Prematur" dalam dalam Sofie R.Krisnadi, Jusuf S. Efendi dan Adhi Pribadi. Prematuritas, pp 43-66. Bandung : Refika Aditama.

10. Saifuddin. 2002. Buku Acuan Nasional Pelayanan Kesehatan Maternal dan Neonatal. Cetakan Ketiga.Jakarta:Yayasan Bina Pustaka.

11. Sistiarani, Colti. 2008. Faktor Maternal dan Kualitas Pelayanan Antenatal yang Berisiko Terhadap Kejadian Berat Badan Lahir Rendah (BBLR). Tesis Universitas Diponegoro Semarang.

12. Sulistyowati, A. 2008. Hubungan Antara Faktor Determinan Ibu dengan Kejadian Persalinan Prematur di RSU. Dr. Saiful Anwar Malang 2008. Karya Tulis IImiah Universitas Airlangga Surabaya.

13. Varney, H. 2007. Buku Ajar Asuhan Kebidanan. Jakarta: EGC.

14. Mochtar, R. 2002. Syinopsis Obstetri. Edisi II. Jakarta: EGC. 